\title{
Análisis comparativo de la evapotranspiración para el cálculo de la demanda hídrica de café en la parte alta de la cuenca del río Santa María
}

\author{
Castillo, Karoline \\ Universidad de Panamá y Creho Ramsar \\ Chiriquí, Panamá \\ Karoline1416@outlook.com \\ Ortega, Richard \\ Universidad de Panamá \\ Chiriquí, Panamá \\ richard.ortega@up.ac.pa \\ De León, Conrado \\ Creho Ramsar \\ Veraguas, Panamá \\ conrado.deleon09@gmail.com
}

\begin{abstract}
The crop of coffee is the productive system that prevails in the upper part of the Santa María river basin and farmers must improve production in times of drought due to the scarcity of water. In this context, the objective is to analyze and compare evapotranspiration to calculate the water demand for coffee in three farms located in the province of Veraguas. This requires the calculation of the reference crop evapotranspiration (ETo), with the PenmanMonteith method and Landsat satellite images, then obtaining the crop evapotranspiration (ETC) and finally estimating the water demand requirements.

The evapotranspiration of the reference crop was obtained using the CROPWAT software, with data from two meteorological stations (ETESA and one station installed in the field) and satellite images from the METRIC EEFLUX website processed in ArcGIS Pro. The irrigation requirements of the coffee crop for a probability of occurrence of $90 \%$ of ETo and precipitation, the ETESA station was used, which resulted in lower values in December and higher values in March (0,34 and 0,53 I/ s / ha). These results suggest that in order to establish coffee cultivation in the dry season it will be necessary to irrigate the crops since the precipitation is not enough to supply it.
\end{abstract}


Keywords: Evapotranspiration of the crop, evapotranspiration of the reference crop, coffee, irrigation need and satellite images.

\section{Resumen}

El cultivo de café es el sistema productivo que prevalece en la parte alta de la cuenca del río Santa María y los agricultores deben mejorar la producción en época de sequía debido a la escasez de agua. En este contexto, el objetivo es analizar y comparar la evapotranspiración para el cálculo de la demanda hídrica de café en tres fincas ubicadas en la provincia de Veraguas. Para ello se necesita el cálculo de la evapotranspiración del cultivo de referencia (ETo), con el método de Penman-Monteith e imágenes satelitales Landsat, luego obtener la evapotranspiración del cultivo (ETc) y por último estimar los requerimientos de la demanda de agua.

La evapotranspiración del cultivo de referencia se obtuvo mediante el software CROPWAT, con datos de dos estaciones meteorológicas (ETESA y una estación instalada en campo) e imágenes satelitales de la página web METRIC EEFLUX procesadas en ArcGIS Pro. Los requerimientos de riego del cultivo de café, para una probabilidad de ocurrencia del $90 \%$ de ETo y precipitación, se utilizó la estación de ETESA donde resultó valores más bajos en diciembre y más altos en marzo $(0,34$ y $0,53 \mathrm{l} / \mathrm{s} / \mathrm{ha})$. Estos resultados sugieren que para poder establecer el cultivo de café en la época seca será necesario regar los cultivos ya que la precipitación no es suficiente para abastecer el mismo.

Palabras claves: Evapotranspiración del cultivo de referencia, evapotranspiración del cultivo, café, necesidad de riego e imágenes Satelitales.

\section{INTRODUCCIÓN}

La evapotranspiración es la cantidad máxima de agua que puede evaporarse desde un suelo cubierto de vegetación, desarrollado en óptimas condiciones. En otras palabras, la evapotranspiración es la suma de la evaporación y la transpiración: la evaporación es la pérdida de agua en forma de vapor del suelo y la transpiración es la pérdida de agua que se encuentra en el tejido de la planta. Este factor es de gran importancia en la agricultura, ya que permite conocer sí el cultivo presenta un déficit de agua y si requiere de un sistema de riego para mejorar la eficiencia en su uso ${ }^{[1]}$.

La población en la parte alta de la cuenca del río Santa María se dedica a la agricultura en pequeña escala utilizando sistemas agroforestales diversificados, dentro de los cuales 
la más importante es la producción de café. En el área existen más de 1000 productores cafetaleros, además cuentan con la Cooperativa La esperanza de los Campesinos quién está conformada por más de 400 pequeños caficultores en donde acopian sus granos de café ${ }^{[2]}$.

Sin embargo, el principal problema de los agricultores de las pequeñas fincas cafetaleras es que no cuentan con información confiable de la demanda de agua para su cultivo y tanto el déficit como el exceso en el suelo afectan la producción. Al mismo tiempo, la posible disminución de los rendimientos de productos agrícolas es ocasionada por la escasez de las lluvias, el aumento en las temperaturas y la poca disponibilidad de agua para los cultivos en época de sequía ${ }^{[3]}$, por tal motivo se debe conocer si la oferta de agua que se cuenta puede suplir la demanda en las pequeñas fincas de café.

Por consiguiente, el objetivo principal de la investigación se centra en analizar y comparar la evapotranspiración para el cálculo de la demanda hídrica del cultivo de café en tres fincas: El Gallo, Alto de Piedra y Pajonal ubicadas en la provincia de Veraguas, mediante la aplicación de metodologías que utilicen datos meteorológicos y herramientas de mapeo basadas en sensores remotos para obtener imágenes satelitales Landsat. De esta forma, no solo beneficiará a los pequeños agricultores de las fincas cafetaleras con información confiable, sino que, también les ayudará a obtener una base de datos sobre la demanda de agua para su cultivo.

\section{MÉTODO}

\section{A. Localización y Descripción del Área}

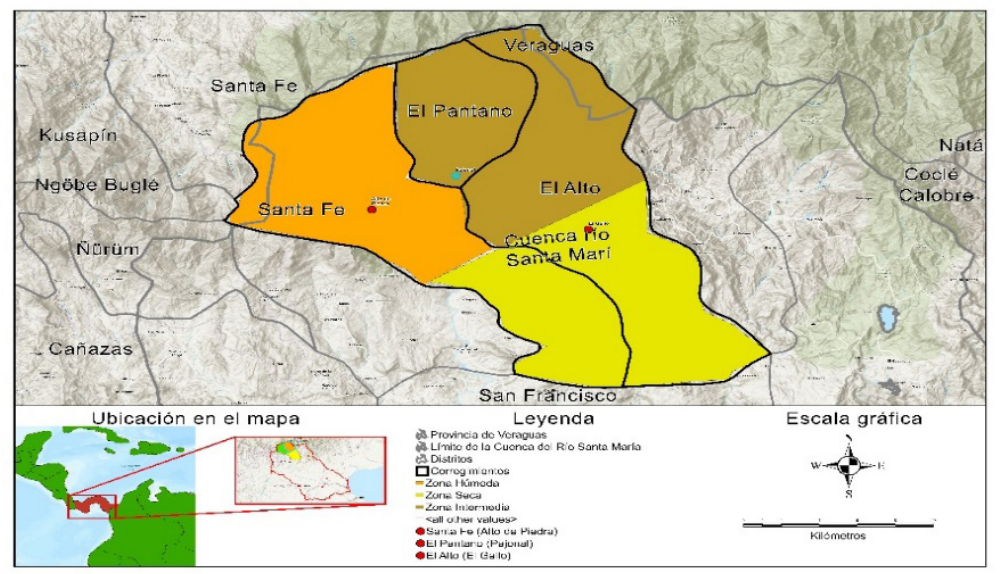

Figura 1. Mapa de localización de las fincas de café e identificación de la zona húmeda, zona intermedia y zona seca del distrito de Santa Fe. Autor: Elaboración propia.

Según reportes de informantes locales y miembros de la Cooperativa la Esperanza de los Campesinos, en el distrito de Santa Fe existe: una zona húmeda, una zona 
intermedia y una zona seca. Para analizar la evapotranspiración de referencia se realizó una dinámica, con miembros de la cooperativa, donde se seleccionó una finca cafetalera por zona. Las tres fincas están ubicadas dentro del distrito de Santa Fe, en los corregimientos de: Santa Fe, comunidad Alto de Piedra, El Pantano, comunidad Pajonal y El Alto, comunidad El Gallo.

Las fincas serán nombradas por corregimiento y comunidad. A continuación, se describen las fincas:

- Finca Santa Fe, Alto de Piedra: se localiza geográficamente a 8.52 latitud norte y-81.12 longitud oeste con una elevación de 816 msnm y un área cultivada de 1.04 hectáreas. La cual está cultivada con café Coffea arabica, variedades: obata y marsellesa, sin sombra; la densidad de siembra del café es de 2,888 plantas/hectárea.

- Finca El Pantano, Pajonal: se localiza geográficamente a 8.53 latitud norte y -81.07 longitud oeste con una elevación de 296 msnm y un área cultivada de 0.37 hectáreas. La cual está cultivada con café Coffea canephora y Coffea arabica, variedades: robusta, obata y caturra, con sombra; la densidad de siembra del café es de 852 plantas/ hectárea.

- Finca El Alto, El Gallo: se localiza geográficamente a 8.50 latitud norte y -81.03 longitud oeste con una elevación de 426 msnm y un área cultivada de 0.64 hectáreas. La cual está cultivada con café Coffea arabica, variedades: caturra, catimor y castillo, con sombra; la densidad de siembra del café es de 1777 plantas/hectárea.

\section{B. Evapotranspiración de referencia ( $\mathrm{ET}_{\mathrm{o}}$ )}

Para la adquisición de datos geoespaciales de las imágenes satelitales que contienen la evapotranspiración (ETo) calculadas con el método de Penman-Monteith FAO, sujetas a las fechas de paso del satélite Landsat 7, fueron extraídas de la aplicación web Earth Engine Evapotranspiration Flux (EEFlux) para las tres fincas de estudio en los 5 meses de sequía comprendidos de diciembre 2020 hasta abril 2021 y luego fueron procesadas a través del programa ArcGIS Pro. 


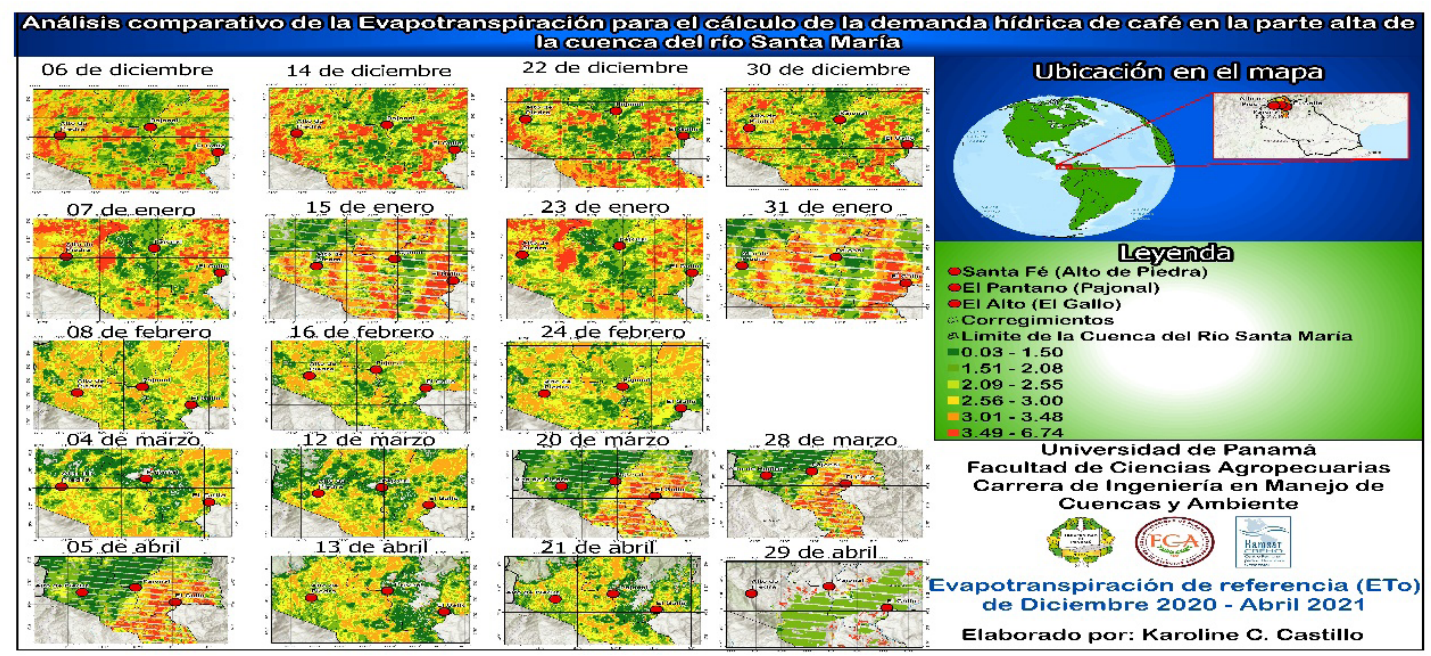

Figura 2. Evapotranspiración de referencia (ETo) de las tres fincas ubicadas en el distrito de Santa Fe, para los medes de diciembre 2020 hasta abril 2021. Nótese que la ETo más alta es de color naranja y la ETo más baja es de color verde. Autor: Elaboración propia.

Se instaló una estación meteorológica el 12 de diciembre del 2020 en la finca El Pantano, Pajonal para analizar y comparar la ET ocon las imágenes satelitales. De la estación se recolectaron datos de temperatura máxima, temperatura mínima, humedad relativa, viento, radiación solar e insolación, luego se calculó la ET con el programa CROPWAT 8.0 que utiliza la ecuación Penman-Monteith metodología recomendada por la FAO ${ }^{[4]}$.

\section{Determinación de la evapotranspiración}

Después de aplicar la metodología que calcula la $\mathrm{ET}_{\mathrm{o}}$ recomendada por la FAO con la ecuación de Penman-Monteith ${ }^{[4]}$.

$$
\boldsymbol{E T}_{\boldsymbol{o}}=\frac{0.408 \Delta\left(R_{n}-G\right)+\gamma \frac{900}{T+273} u_{2}\left(e_{s}-e_{a}\right)}{\Delta+\gamma\left(1+0.34 u_{2}\right)} /
$$

\section{Donde}

$\mathrm{ET}_{\mathrm{o}}=$ Evapotranspiración de referencia $\left(\mathrm{mm} \mathrm{dí}^{-1}\right)$,

$\mathrm{R}_{\mathrm{n}}=$ Radiación neta en la superficie del cultivo ( $\mathrm{MJ} \mathrm{m}^{-2}$ día $^{-1}$ ),

$\mathrm{G}=$ Densidad de flujo de calor del suelo $\left(\mathrm{MJ} \mathrm{m}^{-2}\right.$ día $\left.^{-1}\right)$,

$\mathrm{T}=$ Temperatura del aire a $2 \mathrm{~m}$ altura $\left({ }^{\circ} \mathrm{C}\right)$,

$\mathrm{u}_{2}=$ Velocidad del viento a $2 \mathrm{~m}$ de altura $\left(\mathrm{ms}^{-1}\right)$, 
$\mathrm{e}_{\mathrm{s}}=$ Presión de saturación $(\mathrm{kPa})$,

$\mathrm{e}_{\mathrm{a}}=$ Presión de vapor real $(\mathrm{kPa})$,

$\mathrm{e}_{\mathrm{s}}-\mathrm{e}_{\mathrm{a}}=$ Déficit de presión de vapor de saturación $(\mathrm{kPa})$,

$\Delta=$ Pendiente curva de presión de vapor $\left(\mathrm{kPa}^{\circ} \mathrm{C}^{-1}\right)$,

$\mathrm{g}=$ Constante psicrométrica $\left(\mathrm{kPa}{ }^{\circ} \mathrm{C}^{-1}\right)$.

Se utilizó una serie de datos meteorológicos de 33 años consecutivos de la estación de ETESA ubicada en Santa Fe localiza geográficamente a 9.00 latitud norte y -81.45 longitud oeste utilizando los parámetros de temperatura máxima, temperatura mínima, humedad relativa, viento, radiación solar e insolación para el cálculo de la evapotranspiración recomendados por la FAO ${ }^{[4]}$. Debido a la falta de datos en algunos meses de realizo una interpolación de datos para realizar el relleno. Luego se calculo la probabilidad de ocurrencia del $90 \%$ de ET y precipitación con el programa INFOSTAT. La distribución de datos que se utilizó se ajusta al modelo según el mes, tanto para la $\mathrm{ET}_{0}$ y precipitación con el objetivo de observar su impacto en las necesidades de riego.

Evapotranspiración del cultivo ( $\mathrm{ET}_{\mathrm{c}}$ ) y la demanda de agua

Ecuación para el cálculo de la $\mathrm{ET}_{\mathrm{c}}{ }^{[4]}$.

\section{$\boldsymbol{E T _ { c }}=E T_{o} * K c$}

Donde

$\mathrm{ET}_{\mathrm{c}}=$ Evapotranspiración del cultivo (mm día $\left.{ }^{-1}\right)$,

$\mathrm{ET}_{\mathrm{o}}=$ evapotranspiración del cultivo de referencia $\left(\mathrm{mm} \mathrm{día}^{-1}\right)$,

$\mathrm{Kc}=$ Coeficiente de cultivo (adimensional).

Los requerimientos de la demanda de agua para el cultivo de café se calcularon con el programa CROPWAT.

\section{RESULTADOS}

A continuación, se presenta en el cálculo de probabilidad de ocurrencia de ET。 y precipitación las distribuciones que más se ajustaron: normal y Gumbel de la estación de ETESA Santa Fe como se aprecia en la tabla 1. 


\begin{tabular}{|c|c|c|c|c|c|c|c|}
\hline \multicolumn{6}{|c|}{ Tabla. Evapotranspiración del cultivo de referencia (ETo) de la estación ETESA Santa Fe según } \\
la probabilidad de ocurrencia (mm / día). \\
\hline Itm. & $\begin{array}{l}\text { Probabilidad de } \\
\text { ocurrencia / mes }\end{array}$ & $\mathbf{2 0 \%}$ & Meses & $\mathbf{8 0 \%}$ & $\mathbf{9 0 \%}$ & Distribución & r \\
\hline $\mathbf{1}$ & Enero & 3.20 & 3.33 & 3.51 & 3.63 & Gumbel & 0.991 \\
\hline $\mathbf{2}$ & Febrero & 3.60 & 3.79 & 3.97 & 4.06 & Normal & 0.984 \\
\hline $\mathbf{3}$ & Marzo & 4.52 & 4.72 & 4.91 & 5.01 & Normal & 0.990 \\
\hline $\mathbf{4}$ & Abril & 4.06 & 4.25 & 4.44 & 4.54 & Normal & 0.985 \\
\hline $\mathbf{5}$ & Mayo & 3.80 & 3.94 & 4.08 & 4.16 & Normal & 0.987 \\
\hline $\mathbf{6}$ & Junio & 3.62 & 3.74 & 3.87 & 3.94 & Normal & 0.990 \\
\hline $\mathbf{7}$ & Julio & 3.59 & 3.72 & 3.85 & 3.92 & Normal & 0.979 \\
\hline $\mathbf{8}$ & Agosto & 3.72 & 3.81 & 3.94 & 4.02 & Gumbel & 0.994 \\
\hline $\mathbf{9}$ & Septiembre & 3.71 & 3.83 & 3.96 & 4.03 & Normal & 0.979 \\
\hline $\mathbf{1 0}$ & Octubre & 3.36 & 3.48 & 3.60 & 3.66 & Normal & 0.994 \\
\hline $\mathbf{1 1}$ & Noviembre & 3.06 & 3.20 & 3.35 & 3.42 & Normal & 0.980 \\
\hline $\mathbf{1 2}$ & Diciembre & 3.01 & 3.16 & 3.31 & 3.39 & Normal & 0.987 \\
\hline
\end{tabular}

Tabla 1. Tabla de probabilidad de ocurrencia de la ETo según los datos de ETESA Santa Fe

\begin{tabular}{|c|c|c|c|c|c|c|c|}
\hline Itm. & $\begin{array}{l}\text { Probabilidad de } \\
\text { ocurrencia / mes }\end{array}$ & $20 \%$ & $50 \%$ & $80 \%$ & $\mathbf{9 0 \%}$ & Distribución & $\mathbf{r}$ \\
\hline 1 & Enero & 15.37 & 38.06 & 68.58 & 88.79 & Gumbel & 0.968 \\
\hline 2 & Febrero & 5.53 & 21.50 & 43.00 & 57.23 & Gumbel & 0.837 \\
\hline 3 & Marzo & 12.78 & 30.53 & 54.42 & 70.24 & Gumbel & 0.958 \\
\hline 4 & Abril & 29.70 & 61.93 & 105.30 & 134.02 & Gumbel & 0.981 \\
\hline 5 & Mayo & 233.35 & 321.86 & 410.37 & 456.64 & Normal & 0.986 \\
\hline 6 & Junio & 180.04 & 255.11 & 330.18 & 369.42 & Normal & 0.995 \\
\hline 7 & Julio & 127.97 & 195.48 & 286.32 & 346.46 & Gumbel & 0.991 \\
\hline 8 & Agosto & 223.66 & 232.03 & 240.40 & 244.78 & Normal & 0.990 \\
\hline 9 & Septiembre & 244.96 & 326.41 & 407.86 & 450.44 & Normal & 0.991 \\
\hline 10 & Octubre & 246.09 & 325.16 & 431.55 & 501.99 & Gumbel & 0.989 \\
\hline 11 & Noviembr & 143.06 & 214.48 & 310.57 & 374.19 & Gumbel & 0.994 \\
\hline 12 & Diciembre & 50.00 & 105.02 & 179.06 & 228.07 & Gumbel & 0.977 \\
\hline
\end{tabular}

Tabla 2. Tabla de probabilidad de ocurrencia de la precipitación según los datos de ETESA Santa Fe.

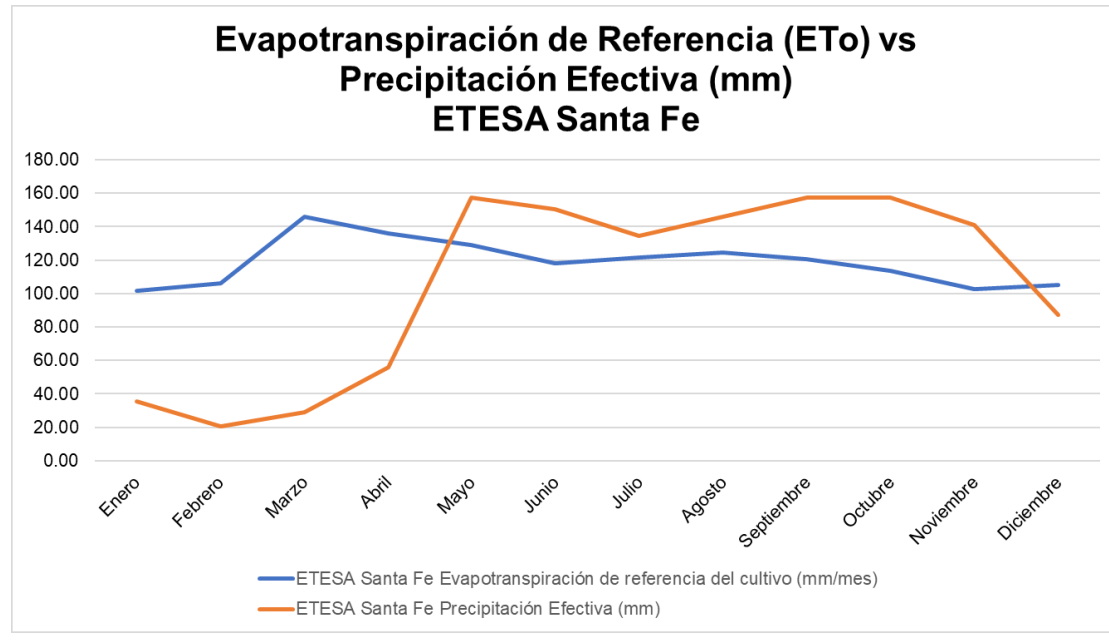

Gráfica 1. Evapotranspiración de referencia y la precipitación efectiva según los datos de ETESA Santa Fe. 


\section{CONCLUSIONES}

Los requerimientos de riego del cultivo de café, para una probabilidad de ocurrencia del $90 \%$ de ET y precipitación, se utilizó la estación de ETESA donde resultó valores más bajos en diciembre y más altos en marzo $(0,34$ y $0,53 \mathrm{l} / \mathrm{s} / \mathrm{ha})$. Estos resultados sugieren que para poder establecer el cultivo de café en la época seca será necesario regar los cultivos ya que la precipitación no es suficiente para abastecer el mismo. En el mes de abril no se observa requerimientos de riego, ya que la precipitación puede suplir las necesidades de agua.

Se recomienda no utilizar las imágenes satelitales en áreas muy nubosas como el distrito de Santa Fe, ya que puede influir en la obtención de datos, en el caso del estudio la correlación entre ambos datos fue muy baja.

\section{Referencias}

[1] J. Sánchez, Evapotranspiración, España: Universidad de Salamanca, 2015.

[2] F. Pineda (comunicación privada), miembro de la cooperativa La Esperanza de los campecinos, 2020.

[3] MI AMBIENTE, "Estrategia Nacional de Cambio Climático,2050", Revista de Obras Públicas, Vol. 166, 2019.

[4] R. Allen, L. Pereira, D. Raes and M. Smith, Evapotranspiración del cultivo Guías para la determinación de los requerimientos de agua de los cultivos. Estudio fao riego y drenaje 56, 2006.

\section{Autorización y Licencia CC}

Los autores autorizan a APANAC XVIII a publicar el artículo en las actas de la conferencia en Acceso Abierto (Open Access) en diversos formatos digitales (PDF, HTML, EPUB) e integrarlos en diversas plataformas online como repositorios y bases de datos bajo la licencia, Attribution-NonCommercialShareAlike 4.0 International (CC BY-NC-SA 4.0) https://creativecommons.org/licenses/by-nc-sa/4.0/.

Ni APANAC XVIII ni los editores son responsables ni del contenido ni de las implicaciones de lo expresado en el artículo. 